\title{
Avaliação de impacto do regime especial de tributação Recap nas importações de bens de capital de 2004 a 2013
}

\author{
Thiago Fernandes Ladeira* \\ Leonardo Chaves Borges Cardoso**
}

\begin{abstract}
Resumen
Este trabajo presenta una estimación del impacto del Régimen Especial de Adquisición de Bienes de Equipo para Empresas Exportadoras (Recap) sobre la importación de bienes de capital por parte del país, como parte de los esfuerzos emprendidos en el ámbito de la Política Industrial, Tecnológica y de Comercio Exterior (PITCE). Para ello, estima los determinantes de la demanda de importaciones de los productos beneficiados por el régimen y evalúa si la exención tributaria introducida fue significativa para incrementar la demanda externa de esos rubros.
\end{abstract}

Palabras clave: Recap. Demanda de importaciones. Exención fiscal. Política industrial.

* Mestre em Economia Aplicada pela UFV. E-mail: fernandesladeira@hotmail.com

** Doutor em Desenvolvimento Econômico pela UFPR. Professor Adjunto no DER/UFV. E-mail: leonardocardoso005@gmail.com

http://dx.doi.org/10.5335/rtee.v25i53.8691

Submissão: 27/09/2018. Aceite: 18/09/2020. 


\section{Introdução}

Eivadas de controvérsias, as discussões acerca da adoção ou abandono de políticas públicas que objetivem intervir no ambiente econômico pautam, sobremaneira, a agenda da pesquisa em economia. Se, por um lado, economistas de orientação neoclássica advogam a execução de políticas econômicas que busquem, tão somente, remover ou minimizar falhas de mercado, por outro, economistas heterodoxos avaliam com maior criticidade a análise empírica e prescrevem intervenções públicas mais efetivas onde o sistema de mercado não opera eficientemente ou exista motivação estratégica no bojo de um programa de desenvolvimento econômico maior.

Entre os inúmeros instrumentos de política econômica à disposição da tecnocracia nacional para a promoção do crescimento e desenvolvimento econômicos repousa o conjunto de medidas e ações públicas que visam orientar a alocação de recursos no circuito intraindustrial, buscando promover ou desestimular atividades econômicas e cadeias produtivas em escala tanto macro quanto microeconômica. A este conjunto de ações atribui-se o dístico de política industrial (PI).

A PI brasileira, a partir do pós-guerra, esteve amplamente voltada para o programa de substituição de importações. Emoldurada pelas diretrizes do Plano de Metas e do II Plano Nacional de Desenvolvimento, já sob o comando autoritário da ditadura militar, esteve, num primeiro turno, voltada para a complementação da matriz industrial brasileira e, ulteriormente, para a promoção de exportações e o equilíbrio do balanço de pagamentos.

Após a abertura democrática e as instabilidades macroeconômicas que, em parte, dela resultaram, a década de 1980 observou uma inflexão no planejamento industrial que se submeteu à lógica estabilizante do cenário econômico. Foi o início do relativo ostracismo das políticas de industrialização que teve somente na tímida Nova Política Industrial do governo Sarney (1988) alguma relevância estratégica.

A partir de 1990, com a investidura de Fernando Collor à Presidência da República, a PI assumiu nova interpretação e teve nos ganhos de produtividade e na inserção externa suas novas diretrizes (BRASIL, 1990).

É no contexto do governo Fernando Henrique Cardoso que a PI se torna quase totalmente inviabilizada em função das prioridades macroeconômicas e a adoção da taxa de câmbio como variável de estabilização dos preços internos ${ }^{1}$.

Contudo, a partir de 2003, o planejamento industrial e a promoção de exportações são ressignificados pelo governo Lula, e um novo conjunto de instrumentos de 
PI é construído na tentativa de retomar algum protagonismo da atividade industrial e exportadora brasileira (BRASIL, 2003).

Dentro desse conjunto, pode-se destacar algumas medidas de promoção de exportações via suspensão tarifária de tributos cobrados na importação de bens de capital por empresas exportadoras. Nessas circunstâncias, dois regimes fiscais foram criados no intento de alavancar as exportações brasileiras. São eles: o Regime Especial de Tributação para a Plataforma de Exportação de Serviços de Tecnologia da Informação (Repes) e o Regime Especial de Aquisição de Bens de Capital para Empresas Exportadoras (Recap), que concederam suspensão da cobrança do PIS/ Pasep e da Cofins, além do IPI (no caso do Repes) na importação ou aquisição no mercado interno de bens de capital por empresas exportadoras. Ambos os regimes envolvem percentuais consideráveis de renúncia fiscal, uma vez que se tratam de impostos com cobrança ad valorem, podendo chegar a aproximadamente $27 \%$ do valor do produto ${ }^{2}$.

Diante do exposto, o presente artigo buscará avaliar os impactos do Recap no que tange à promoção da importação de máquinas e equipamentos através das renúncias fiscais instituídas através do método de diferenças-em-diferença (DD), bem como dos determinantes da demanda destes bens quando se comparam duas amostras: uma contendo produtos beneficiados (grupo de tratamento) pelo regime e um contrafactual (grupo de controle) não beneficiado, no período compreendido entre janeiro de 2004 e dezembro de 2013.

Para tanto, a próxima seção apresentará uma contextualização do Recap em seus aspectos legais e operacionais. Em seguida, a metodologia do estudo será apresentada juntamente com o modelo analítico e o referencial teórico. Na terceira seção, os resultados das estimativas serão apresentados para fins de análises e ponderações. Comentários e avaliações seguirão à guisa de conclusão.

\section{Revisão bibliográfica}

O Brasil ainda carece de trabalhos empíricos sobre a análise de impactos de reformas em políticas tributárias e tarifárias. Costa et al. (2008) estudaram o caso específico de alterações dos regimes de apuração do PIS/Pasep e da Cofins e o consequente impacto destas alterações no resultado operacional de uma amostra de empresas do setor de gêneros alimentícios. O resultado apresentado indica um efeito negativo substancial sobre o lucro das companhias consideradas. 
Theodoro e Scorzafave (2011) avaliaram o impacto da redução dos encargos trabalhistas promovida em 2006 pela Lei n⿳0 11.324 sobre a formalização do emprego doméstico e apontaram para uma possível inconclusão a respeito da eficácia das desonerações implementadas, dado o lapso temporal necessário para assimilar as vantagens decorrentes do advento da lei.

Calzolaio e Dathein (2012), por sua vez, analisaram o impacto das políticas fiscais de incentivo à inovação à luz da Lei n⿳o 11.196/2005 e concluíram que esses incentivos promovem uma espécie de seleção adversa ao contemplar somente empresas optantes pelo lucro real, mormente as de grande porte, e não amplia, com isso, a base de empresas que fazem inovação tecnológica no país. Resultado similar ao encontrado por esta pesquisa no que tange ao Recap como indutor dos investimentos produtivos das empresas exportadoras brasileiras.

Finalmente, Mattos, Rocha e Toporcov (2013) investigaram o impacto do Programa Nota Fiscal Paulista sobre a arrecadação do estado de São Paulo, concluindo que o incentivo fiscal tem um efeito positivo e significativo, principalmente, sobre a arrecadação do setor terciário.

\section{Contextualização}

\section{A Lei no 11.196/2005 - denominada "Lei do Bem"}

Na esteira da retomada do planejamento industrial e objetivando conferir materialidade às diretrizes da política industrial, a Lei $\mathrm{n}^{0}$ 11.196, que incorporou ao seu texto as disposições contidas nas Medidas Provisórias 252/2005 e 255/2005, foi promulgada em 21 de novembro de 2005 e regulamentada pelo Decreto $\mathrm{n}^{\mathrm{o}}$ 5.649/2005 e pela Instrução Normativa 605/2006 da Receita Federal. Plural em seu escopo, o texto legal versa extensamente sobre temas variados que abarcam a continuação do Repes e do Recap, do Programa de Inclusão Digital, dos incentivos fiscais para a inovação tecnológica, entre outros.

Com efeitos produzíveis a partir de novembro de 2005, o Recap contemplou uma reduzida base de beneficiários potenciais, uma vez que a adesão ficou restrita aos contribuintes optantes pelo regime de apuração do Lucro Real, conforme veremos adiante - o que correspondia a aproximadamente $6 \%^{3}$ do total de pessoas jurídicas cadastradas na Receita Federal do Brasil (RFB). 


\section{O Recap como política de incentivo à exportação}

O financiamento, a simplificação de processos e a desoneração tributária passaram a ser entendidos como instrumentos de inserção externa e ganhos de produtividade da produção industrial brasileira e medida necessária para alavancar as exportações do país. (BRASIL, 2003).

$\mathrm{O}$ artifício da desoneração tributária, assim compreendida como o conjunto de incentivos ou regimes fiscais específicos para produtos ou operações, viabilizando redução da carga fiscal de produtos, operações ou um conjunto de atividades sujeitas à tributação (O PORTAL TRIBUTÁRIO, 2013), pode, dentro de um contexto mais amplo, conferir competitividade e estimular a demanda externa de produtos nacionais pela via da redução dos custos de produção ou do preço de venda de produtos e serviços.

Conforme exposto na Exposição de Motivos (EM) Interministerial 84/05 - MF/ MDIC, o alinhamento do Recap com a com a política industrial e de comércio exterior fica evidente:

5. A criação do RECAP visa incentivar o investimento produtivo e a ampliação das exportações mediante a correção de distorções que oneram o custo dos bens de capital das empresas preponderantemente exportadoras. Esse regime suspende a incidência da Contribuição para o PIS/PASEP e da COFINS nas vendas e na importação de máquinas, aparelhos, instrumentos e equipamentos novos, relacionados em regulamento, quando adquiridos por pessoas jurídicas preponderantemente exportadoras. A exemplo do REPES, o RECAP visa eliminar o acúmulo de créditos de PIS e COFINS por empresas exportadoras, complementando o dispositivo já previsto no art. 40 da Lei $\mathrm{n}^{\mathrm{o}}$ 10.865, de 30 de abril de 2004, que suspende a incidência das contribuições nas vendas de matérias-primas, produtos intermediários e materiais de embalagem quando destinados às pessoas jurídicas preponderantemente exportadoras (BRASIL, 2005, p. 1).

As condições especiais de tributação que passariam a beneficiar empresas exportadoras envolveram, em suma, a redução a zero dos seguintes tributos incidentes sobre a venda ou importação de máquinas, aparelhos, instrumentos e equipamentos, novos:

i) da contribuição para o PIS/Pasep e a Cofins incidentes sobre a receita bruta da venda no mercado interno, quando os referidos bens forem adquiridos por pessoa jurídica beneficiária do Recap para incorporação ao seu ativo imobilizado;

ii) da contribuição PIS/Pasep-Importação e da Cofins-Importação, quando os referidos bens forem importados diretamente por pessoa jurídica beneficiária do Recap para incorporação ao seu ativo imobilizado. 


\section{Os enquadramentos necessários}

Os critérios para habilitação ao Recap abrangem duas dimensões básicas. $\mathrm{Na}$ esfera constitutiva da empresa, a IN SRF $n^{\circ}$ 680/2006 estabelece:

Art. $4^{\circ}$ A habilitação de que trata $o$ art. $3^{\circ}$ somente pode ser requerida por:

I - pessoa jurídica preponderantemente exportadora de que trata 0 art. $5^{\circ}$;

II - pessoa jurídica que assumir o compromisso de exportação de que trata o art. 6º ; ou

III - estaleiro naval brasileiro, na forma do art. $7^{\circ}$.

Parágrafo único. Não poderá se habilitar ao RECAP a pessoa jurídica:

I - que tenha suas receitas, no todo ou em parte, submetidas ao regime de incidência cumulativa da Contribuição para o PIS/Pasep e da Cofins;

II - optante pelo Sistema Integrado de Pagamento de Impostos e Contribuições das Microempresas e das Empresas de Pequeno Porte (Simples); ou

III - que esteja irregular em relação aos tributos e contribuições administrados pela SRF.

Art. $5^{\circ}$ Considera-se preponderantemente exportadora, para efeito de habilitação ao RECAP, a pessoa jurídica cuja receita bruta decorrente de exportação, para o exterior, no ano-calendário imediatamente anterior ao do requerimento de adesão ao regime, houver sido igual ou superior a $80 \%$ (oitenta por cento) de sua receita bruta total de venda de bens e serviços no período, e que assuma compromisso de manter esse percentual de exportação durante dois anos-calendário.

Art. $6^{\circ}$ A pessoa jurídica em início de atividade ou que não tenha atingido, no ano-calendário imediatamente anterior ao do requerimento de adesão ao regime, o percentual de receita de exportação exigido no art. $5^{\circ}$ pode se habilitar ao RECAP desde que assuma compromisso de auferir, durante o período de 3 (três) anos-calendário, receita bruta decorrente de exportação para o exterior de, no mínimo, $80 \%$ (oitenta por cento) de sua receita bruta total de venda de bens e serviços.

Art. $7^{\circ} \mathrm{O}$ estaleiro naval brasileiro pode se habilitar ao RECAP independentemente de possuir receita bruta de exportação para o exterior ou de efetuar compromisso de exportação (BRASIL, 2006, p. 20).

Adicionalmente, o rol de produtos passíveis de enquadramento encontra-se disposto inicialmente no Decreto $\mathrm{n}^{\mathrm{0}}$ 5.629/2005 e abrange uma ampla gama de bens constantes dos capítulos 73 a 90 da Tabela de Incidência do Imposto sobre Produtos Industrializados (TIPI).

\section{As alíquotas básicas}

Cabe, para o fim pretendido, ressaltar qual fora a magnitude das alíquotas efetivas e as características primordiais dos tributos renunciados no Recap e incidentes sobre importações para que se tenha uma percepção do poder de impacto que tal desoneração seria capaz de produzir na quantidade demandada. 
Introduzidos na legislação tributária através da Lei nº 10.865/2004, o PIS/ Pasep-Importação e a Cofins-Importação tiveram as alíquotas básicas definidas em $2,1 \%$ e $9,65 \%$, respectivamente. Portanto, a renúncia total, considerando os dois impostos somados, poderia levar a uma desoneração de $11,75 \%$ ad valorem.

\subsubsection{Uma justificativa para a intervenção}

Ao final do século XX, o dilema da balança comercial deficitária era uma realidade para os formuladores de política econômica. A trajetória incerta do resultado comercial brasileiro na década de 1990 e no início dos anos 2000 serviu de inspiração retórica e motivação política para a retomada de medidas de incentivo à exportação. Este fato se torna mais retumbante quando lançamos olhos sobre o resultado comercial brasileiro nas décadas recentes. $O$ gráfico da Figura 1 ilustra a questão:

Figura 1 - Balança comercial e de serviços - saldo anual

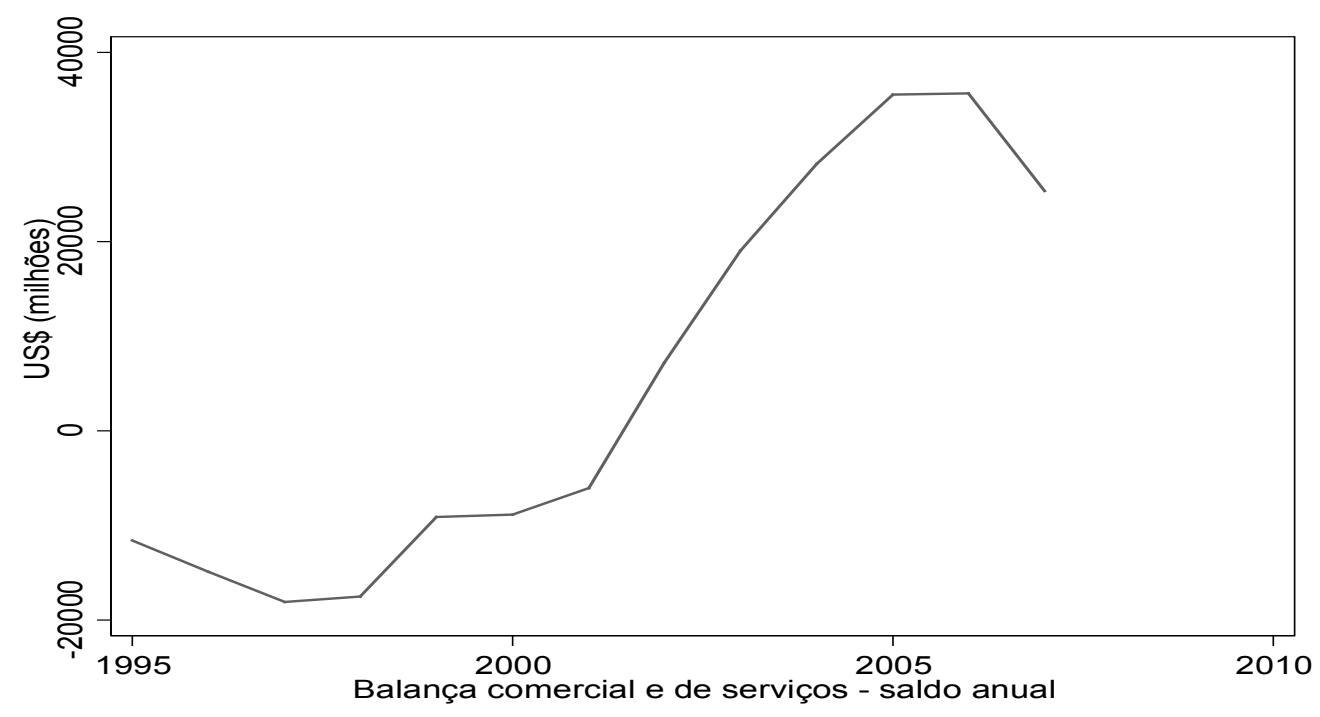

Fonte: Bacen.

Ou seja, o saldo da balança comercial brasileira fica em território positivo somente a partir de meados da década de 2000, quando considerada a série iniciada em 1995. 


\section{Metodologia}

\section{O estimador de diferenças-em-diferença (DD)}

Variações no ambiente econômico que alterem o comportamento dos agentes por meio de mudanças em políticas públicas são denominadas experimentos naturais e permitem ao pesquisador avaliar a magnitude dessas alterações através de observações em diferentes momentos no tempo para diferentes grupos de tratamento e de controle (NERI; MEDRADO, 2010). Entretanto,

[...] [é] importante lembrar que o experimento natural é um modelo quase-experimental, isto é, os membros do grupo afetado pela política pública e os do grupo excluído não foram selecionados aleatoriamente. As características de ambos os grupos são semelhantes, mas, por estarem separados fisicamente, uns foram beneficiados pelo programa governamental e outros não (MENEGUIN; FREITAS, 2013, p. 13).

E o método de diferenças-em-diferença (DD) serve ao propósito de mensurar o resultado desses experimentos nas variáveis de interesse.

Tal como apresentado por Blundell e Dias (2000), o método DD consiste na avaliação de impacto a partir da diferença apurada pelo valor médio do resultado da variável dependente para indivíduos tratados antes e depois da intervenção subtraída da diferença dos resultados para indivíduos não tratados, antes e após a intervenção.

Formalmente, temos:

$$
\hat{\beta}_{D D}=\left(\bar{Y}_{P}^{T}-\bar{Y}_{A}^{T}\right)-\left(\bar{Y}_{P}^{C}-\bar{Y}_{A}^{C}\right)
$$

Em que $\hat{\beta}_{D D}$ é o estimador de diferenças-em-diferença, $\bar{Y}_{P}^{T}$ e $\bar{Y}_{A}^{T}$ são os valores médios da variável de resultado para a amostra tratada (sobrescrito " $T$ ") no período posterior (subscrito " $P$ ") e anterior (subscrito " $A$ ") à intervenção, respectivamente. $\bar{Y}_{P}^{C}$ e $\bar{Y}_{A}^{C}$ representam os valores médios da variável dependente para a amostra de controle ("C") após ("P”) e antes (" $A$ ") da intervenção, respectivamente.

Além disso, considerando $\bar{Y}_{p}^{t}=E(Y \mid X, t, p)$ o valor médio da variável de resultado, em que $X$ corresponde a uma matriz de variáveis explanatórias observáveis, $t$ e $p$ são dummies de tratamento ( $t=1$ para tratados e $t=0$ para não tratados) e período ( $p=0$ para o período anterior ao tratamento e $p=1$ para o período posterior), $\alpha$ e $\gamma$ são os coeficientes associados às variáveis dummies $t$ e $p$ e cumprem a função 
de remover os efeitos de isolados de tratamento e período, respectivamente, e $\beta$ é o parâmetro vinculado a um termo de interação $(t * p)$ que capta o efeito conjunto de tratado e período; ainda, sob a hipótese de $E(\epsilon \mid X, t, p)=0$, temos:

$$
\begin{gathered}
\bar{Y}_{1}^{1}=E(Y \mid X, t=1, p=1)=X^{\prime} \delta+\alpha+\gamma+\beta+E(\epsilon \mid X, t=1, p=1)= \\
X^{\prime} \delta+\alpha+\gamma+\beta \\
\bar{Y}_{0}^{1}=E(Y \mid X, t=1, p=0)=X^{\prime} \delta+\alpha+E(\epsilon \mid X, t=1, p=0)=X^{\prime} \delta+\alpha \\
\bar{Y}_{1}^{0}=E(Y \mid X, t=0, p=1)=X^{\prime} \delta+\gamma+E(\epsilon \mid X, t=0, p=1)=X^{\prime} \delta+\gamma \\
\bar{Y}_{0}^{0}=E(Y \mid X, t=0, p=0)=X^{\prime} \delta+E(\epsilon \mid X, t=0, p=0)=X^{\prime} \delta
\end{gathered}
$$

Implicando que:

$$
\begin{gathered}
E\left(\hat{\beta}_{D D}\right)=\left\{\left[X^{\prime} \delta+\alpha+\gamma+\beta+E(\epsilon \mid X, t=1, p=1)\right]-\right. \\
\left.\left[X^{\prime} \delta+\alpha+E(\epsilon \mid X, t=1, p=0)\right]\right\}- \\
\left\{\left[X^{\prime} \delta+\gamma+E(\epsilon \mid X, t=0, p=1)\right]-\left[X^{\prime} \delta+E(\epsilon \mid X, t=0, p=0)\right]\right\}=\beta .
\end{gathered}
$$

O que assegura que o valor esperado do estimador de DD corresponde ao verdadeiro valor do parâmetro $\beta$.

$\mathrm{O}$ problema primordial referente à metodologia DD é justamente a definição do grupo de controle. Conforme Foguel (2012, p. 102):

A principal hipótese do método de DD é que a trajetória temporal da variável de resultado para o grupo de controle represente o que ocorreria com o grupo tratado, caso não houvesse a intervenção. Naturalmente, essa hipótese não pode ser testada diretamente nos dados, mas uma indicação de sua validade aparece quando as trajetórias dos dois grupos são parecidas com pré-programa.

Nesse sentido, a estratégia adotada consistiu na formulação de uma amostra de produtos classificados na Tabela de Incidência do Imposto sobre Produtos Industrializados (TIPI) nos mesmos capítulos dos produtos abrangidos pelo Recap, 
conforme o Decreto n⿳ 5.789/2005 e a Instrução Normativa 605/2006 da RFB, mas não amparados pelo benefício.

Apesar de ser uma hipótese forte, consideramos que os determinantes da demanda por importação de bens de capital são relativamente homogêneos quando se abstraem características mais específicas dos produtos. Além disso, a possibilidade de seleção das mercadorias pelo código de Nomenclatura Comum do Mercosul (NCM) permitiu extrair produtos para a amostra de controle que dada semelhança de natureza e finalidade poderiam representar o comportamento do grupo tratado na ausência da intervenção.

\section{O modelo analítico}

Deixe agora $M_{t p}$ representar o valor das importações de um dado grupo $t$ ( $t=1$ para o grupo de tratamento e $t=0$ para o grupo de controle) no período $p$ ( $p=1$ para o período após o regime e $p=0$, caso contrário), sendo $M_{t p}$ função da renda interna $\left(R_{t p}\right)$ e da relação entre os preços doméstico e internacional $\left[\left(P_{d} / P_{i}\right)_{t p}\right]$ para o grupo $t$ no período $p$. Na versão multiplicativa de seus argumentos, o modelo assume a seguinte forma:

$$
M_{t p}=\delta_{0}\left(P_{d} / P_{i}\right)_{t p}^{\delta_{2}} R_{t p}^{\delta_{3}}
$$

Em que $\delta_{1}$ e $\delta_{2}$ são a elasticidade-preço e a elasticidade-renda da demanda por importações, respectivamente. Essa especificação segue a proposta de Scalco, Lippi e De Almeida (2015), com base no modelo de Thirlwall (1979), e apresenta uma função de demanda para bens importados de uma determinada economia.

Extraindo os logaritmos naturais de $M_{t p},\left(P_{d} / P_{i}\right)$ e $\left(R_{t p}\right)$ (representados por $m_{t p},\left(p_{d} / p_{i}\right)$ e $\left.r_{t p}\right)$ de ambos os lados; adicionando as variáveis dummies $t$ e $p_{\text {e } o}$ termo de interação $(t * p)$ (que assume valor 1 sempre que o grupo $t=1$ recebe tratamento no período $p=1$ e valor zero, caso contrário) e considerando que $\alpha_{t}, \gamma_{p}$ e $\beta_{D D}$ correspondem aos respectivos coeficientes associados a $t, p$ e $(t * p)$, obtemos a seguinte equação:

$$
m_{t p}=\alpha_{t} t+\gamma_{p} p+\delta_{1}+\delta_{2}\left(p_{d} / p_{i}\right)+\delta_{3} r_{t p}+\beta_{D D}(t * p)+\epsilon_{t p}
$$

Por último, $\delta_{1}=\ln \left(\delta_{0}\right)$ e $\epsilon_{t p}$ representa o termo de erro. 
Os sinais esperados dos coeficientes estimados são os seguintes: $\delta_{2}<0$, no sentido que as importações respondem inversamente a uma valorização da taxa real de câmbio. $\delta_{3}>0$ uma vez que as importações respondem positivamente a variações na renda real. Esperamos que $\beta_{D D}$, o estimador DD, assuma sinal positivo, pois, a priori, o intuito da intervenção é impactar diretamente o valor real das importações. Por fim, $\alpha_{t}, \gamma_{p}$ e $\delta_{1}$ podem assumir qualquer valor.

O formato Log-Log é linear nos parâmetros e permite, portanto, a estimação segundo o método de Mínimos Quadrados Ordinários (MQO).

\section{Fonte de dados}

Todos os dados utilizados neste artigo foram obtidos de fontes secundárias. Aqueles referentes ao valor mensal das importações das amostras de tratamento e controle foram obtidos através do Sistema de Análise das Informações de Comércio Exterior (AliceWeb) do Ministério da Indústria, Comércio Exterior e Serviços (MDIC) e deflacionados pelo índice de preços (série: Importações - bens de capital) da Fundação Centro de Estudos do Comércio Exterior (Funcex). Os dados mensais do PIB em dólares, aqui usados como proxy da renda interna são do Sistema Gerenciador de Séries Temporais (SGS) do Banco Central do Brasil (BCB), deflacionados pelo IPC (índice - Estados Unidos) do Bureau of Labor Statistics - Departament of Labor (BLS), e a série “Taxa de câmbio - efetiva real" (setor: fabricação de máquinas e equipamentos) é oriunda do Ipeadata do Instituto de Pesquisa Econômica Aplicada (Ipea). Todos os dados foram transformados em seus valores constantes com base nos valores médios de 2010 .

\section{Análise dos resultados}

Preliminarmente, apresentamos a Figura 2, que traz a trajetória temporal das importações de bens de capital para o grupo de controle e para o grupo de tratamento. Uma linha vertical foi adicionada para demarcar os períodos pré e pós-tratamento. A Figura 2 sugere tendências pouco distinguíveis para os dois grupos mesmo após o início da intervenção, sinalizando a possibilidade de um impacto nulo ou pouco considerável na trajetória das duas amostras. 
Figura 2 - Valor real das importações dos grupos de controle e tratamento, antes e após a intervenção

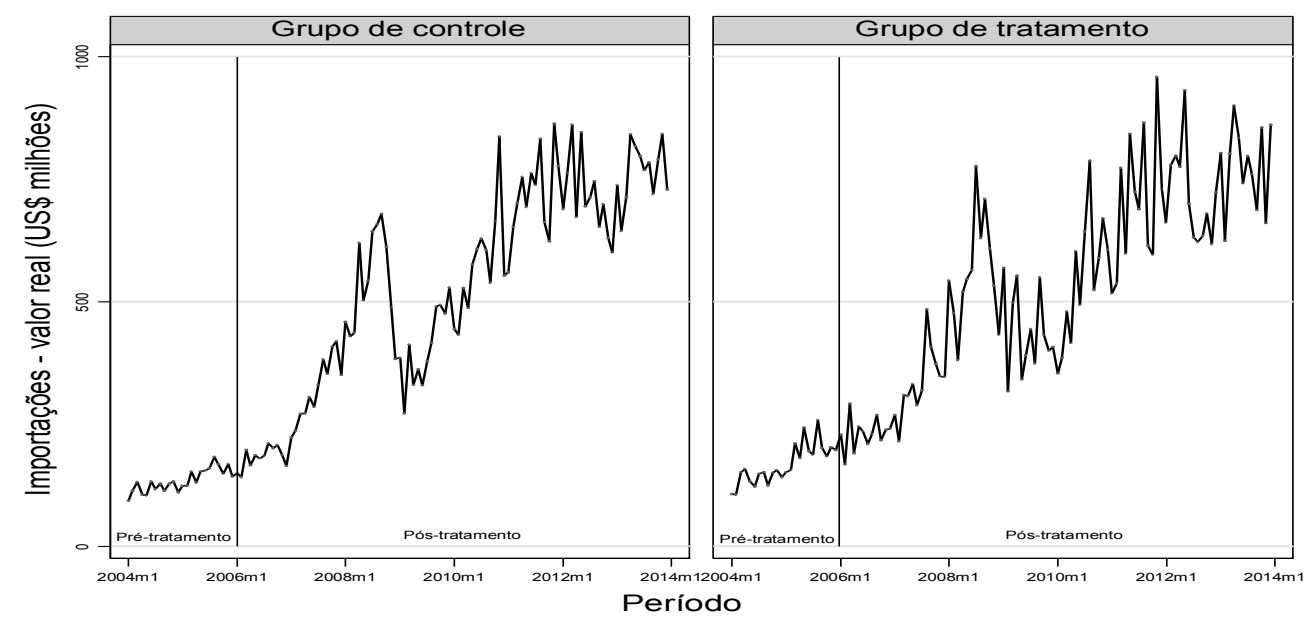

Fonte: dados da pesquisa.

Para confrontar os dados visuais, a Tabela 1 exibe o teste t de diferença de médias com base nos valores em nível das importações e os seguintes apontamentos são levantados: i) no período compreendido entre 2004 e 2005, antes da vigência do regime, a diferença entre as médias do grupo tratado e de controle não foi estatisticamente diferente de zero conforme a estatística t correspondente; ii) o mesmo se aplica ao período após a intervenção (2006-2013); iii) por consequência, o resultado do teste da diferença da diferença (Diff-in-Diff) foi também estatisticamente insignificante e sugere uma possível ineficácia da intervenção.

Tabela 1 - Diferenças em diferenças do efeito sobre os valores absolutos médios da entrada em vigor do Recap

\begin{tabular}{|c|c|c|c|}
\hline Período Recap & Imp real & & № obs. \\
\hline \multicolumn{4}{|l|}{ Antes } \\
\hline Controle & $-115,599$ & & \\
\hline Tratado & $-82,34$ & & 120 \\
\hline Diff (T-C) & 33,26 & $(0,72)$ & \\
\hline Depois & & & 120 \\
\hline Controle & 154,333 & & 120 \\
\hline Tratado & 165,249 & & \\
\hline $\operatorname{Diff}(\mathrm{T}-\mathrm{C})$ & 10,916 & $(0,47)$ & \\
\hline Diff-in-Diff & $-22,344$ & $(0,43)$ & \\
\hline
\end{tabular}

Fonte: elaboração dos autores.

* Estatística $t$ de teste de igualdade de média entre parênteses. 


\section{A estimativa do modelo DD}

A utilização de modelos DD permite fazer a avaliação de impacto de intervenções em séries temporais. Entretanto, Bertrand, Duflo e Mullainathan (2004) advertem para a possibilidade de presença de autocorrelação na estimativa de modelos dessa natureza com consequente ineficiência do estimador obtido por MQO. Dentre as soluções apontadas pelos autores, existe a possibilidade de especificação de um processo autogressivo $(\mathrm{AR}(1))$ na geração do termo de erro e utilização do coeficiente de autocovariância obtido no cômputo do desvio padrão do intervalo de confiança do estimador.

Esse procedimento dá origem a um estimador de Mínimos Quadrados Generalizados (MQG), e os coeficientes calculados a partir deste método foram tabulados conjuntamente com os estimadores de MQO para fins de comparação.

Os coeficientes das regressões estimadas podem ser visualizados na Tabela 2:

Tabela 2 - Coeficientes estimados (variável dependente: $\operatorname{lnimp}$ )

\begin{tabular}{|c|c|c|}
\hline Var. ind. & Coef. (MQO) & Coef. (MQG) \\
\hline cons. & $4,2104 \quad(2,76)^{\ldots * *}$ & $10,03357 \quad(5,56)^{\cdots}$ \\
\hline$p$ & $1,091903 \quad(9,66)^{\cdots *}$ & $0,719614 \quad(4,69)^{\cdots *}$ \\
\hline$t$ & $0,209782 \quad(1,77)$ & $0,122336 \quad(0,63)$ \\
\hline Incamb & $-0,22471 \quad(-0,78)$ & $-0,94504 \quad(-2,57)^{\cdots *}$ \\
\hline Inpib & $0,163556 \quad(4,42)^{\cdots}$ & $-0,01892 \quad(-1,21)$ \\
\hline$D D$ & $-0,17003 \quad(-1,28)$ & $-0,05645 \quad(-0,27)$ \\
\hline no obs.: 240 & $R^{2}: 0,59$ & \\
\hline
\end{tabular}

Fonte: elaboração dos autores.

${ }^{* * *}$ Estatisticamente significante a $1 \%$ de confiança. Entre parênteses as estatísticas de teste.

Diante dos resultados, pode-se concluir que os modelos DD com coeficientes obtidos por MQO e MQG corroboram os resultados do teste de igualdade entre as médias apuradas antes e depois da intervenção, conforme discutido na seção anterior. Em ambos os casos, o valor do estimador obtido não é estatisticamente diferente de zero e evidencia que pode não ter havido qualquer efeito da renúncia fiscal no período analisado. Portanto, se o grupo de controle representa com fidedignidade a trajetória que teria sido tomada pelo grupo de tratamento na ausência 
da intervenção, o resultado da intervenção analisada foi economicamente não substancial.

Quanto às demais variáveis de reposta, o sinal atribuído ao coeficiente do câmbio real (lncamb) apresentou o resultado esperado, apesar de estatisticamente insignificante quando calculado por MQO, porém, pelo método de MQG, ele é estatisticamente significativo ao nível de 5\%. Isso significa que, quando considerado o estimador por MQG, as importações reais de bens de capital do Brasil apresentam elasticidade média próxima à unidade $(0,94 \%)$ em relação às variações no câmbio real.

Já o coeficiente relacionado à renda real (lnpib) é estatisticamente significante para o estimador de MQO e indica que dada uma variação de $1 \%$ no PIB real resulta em um aumento médio de $0,16 \%$ no valor real das importações de bens de capital. Para o estimador de MQG, apesar de apresentar o resultado com o sinal distinto do esperado, ele não foi estatisticamente diferente de zero.

De forma geral, os modelos se mostraram bem ajustados aos dados e sugerem que as variáveis explicativas câmbio e renda exercem efeito considerável na determinação do valor da variável dependente.

\section{Conclusão}

As renúncias fiscais como instrumento de política industrial constituem um tema de alta relevância analítica em virtude dos benefícios setoriais que erigem de suas regras e os valores absolutos e relativos que envolvem. Estimados em R\$ 284,85 bilhões para o ano de 2017 , o que representa $4,2 \%$ do PIB e $21,3 \%$ das receitas administradas pela Receita Federal, segundo dados do Demonstrativo dos Gastos Tributários (DGT) ${ }^{4}$, os gastos tributários no Brasil carecem de uma abordagem profunda que busque reconstruir o caminho que conduz a valores tão expressivos.

A maior dificuldade para tal empreendimento reside na ausência de estatísticas da arrecadação federal de tributos. Inexistem dados em bases confiáveis que forneçam uma série histórica adequada e que contemplem tanto os impostos efetivamente recolhidos quanto aqueles renunciados desagregados setorialmente ou por atividade econômica.

Os resultados deste trabalho indicam que os incentivos fiscais concedidos pelo Recap têm sido insuficientes para alavancar a procura por bens de capital importados pelas empresas exportadoras brasileiras. As demais variáveis explicativas 
(renda e câmbio e demanda externa) mostram-se mais significativas para a determinação das importações de bens de capital.

Uma explicação plausível pode residir nas regras rígidas de habilitação ao regime. Fato que comprime em demasia o universo de empresas potencialmente postulantes ao programa. Atualmente restrito às pessoas jurídicas optantes por Lucro Real e Lucro Presumido (excluídas, portanto, as empresas pequenas e médias optantes pelo regime Simples), com compromisso de exportação igual ou superior a 70\% do faturamento, o Recap conta hoje com a adesão de apenas 365 empresas e gera um provável viés de seleção por permitir que somente empresas maiores possam usufruir dos incentivos fiscais. Ou seja, ao excluir empresas pequenas e médias dos benefícios tributários, o regime fiscal perde sua função, dado que empresas maiores devem levar em consideração quase exclusivamente as condições macroeconômicas de renda e câmbio nas suas decisões de investimento.

Por ser um país sem tradição em setores intensivos em capital, é provável que a maior parte das empresas sediadas no Brasil não possua escala suficiente para suportar a carga tributária vinculada aos regimes de apuração de imposto supracitados, ficando consequentemente à margem dos critérios estabelecidos. Isso não implica que as empresas exportadoras não tenham tido acesso aos bens de capital necessários à inversão produtiva, pois ainda resta o acesso dessas empresas ao mercado interno de máquinas e equipamentos. Todavia, é improvável que a oferta interna seja suficiente para atender toda a demanda.

Assim sendo, é fundamental que se proceda a revisão da legislação que regulamenta o Recap, assegurando que a isonomia permeie as condições de habilitação para que um conjunto maior de empresas exportadoras que são demandantes de bens de capital seja beneficiado pelo regime, possibilitando uma melhor inserção internacional do país em setores capital-intensivos. 


\title{
Impact assessment of the Recap special tax regime on capital goods imports from 2004 to 2013
}

\begin{abstract}
Resumo
Este trabalho apresenta uma estimativa do impacto do Regime Especial de Aquisição de Bens de Capital para Empresas Exportadoras (Recap) sobre a importação de bens de capital pelo país, como parte dos esforços empreendidos no âmbito da Política Industrial, Tecnológica e de Comércio Exterior (PITCE). Para tanto, estima os determinantes da demanda por importação dos produtos beneficiados pelo regime e avalia se a renúncia fiscal introduzida foi significativa para incrementar a procura externa daqueles itens.

Palavras-chave: Recap. Demanda por importação. Renúncia fiscal. Política industrial.

\section{Evaluación de impacto del régimen fiscal especial Recap sobre las importaciones de bienes de capital de 2004 a 2013}

\begin{abstract}
This work presents an estimate of the impact of the Special Regime for the Acquisition of Capital Goods for Exporting Companies (Recap) on the import of capital goods by the country, as part of the efforts undertaken within the scope of the Industrial, Technological and Foreign Trade Policy (PITCE). To this end, it estimates the determinants of the demand for imports of the products benefited by the regime and assesses whether the tax waiver introduced was significant to increase the external demand for those items.
\end{abstract}

Keywords: Recap. Import demand. Tax waiver. Industrial policy.

Classificação JEL: F13

\section{Notas}

1 "A melhor política industrial é não ter política industrial." A frase do ex-ministro da Fazenda, Pedro Malan, é representativa da ideologia dominante à época.

2 No caso específico de Repes, as suspensões aludidas são: PIS/Pasep, 2,1\%, Cofins, 9,65\%, e IPI, alíquota média de $15 \%$. Totalizando $26,75 \%$.

3 Dados agregados oriundos da Declaração de Imposto de Renda da Pessoa Jurídica (IRPJ). Dados disponíveis de 1997 a 2003.

4 Disponível em: http://idg.receita.fazenda.gov.br/dados/receitadata/renuncia-fiscal/previsoes-ploa/dgt-ploa-2017-versao-1-1.pdf. 


\section{Referências}

BERTRAND, Marianne; DUFLO, Esther; MULLAINATHAN, Sendhil. How much should we trust differences-in-differences estimates? The Quarterly Journal of Economics, v. 119, n. 1, p. 249-275, 2004.

BLUNDELL, Richard; DIAS, Monica Costa. Evaluation methods for non $\square$ experimental data. Fiscal Studies, v. 21, n. 4, p. 427-468, 2000.

BRASIL. Casa Civil da Presidência da República. Diretrizes de política industrial, tecnológica e de comércio exterior. Brasília: Casa Civil, 2003.

BRASIL. Casa Civil da Presidência da República. EM Interministerial no 00084/2005 - MF MDIC. Brasília: Casa Civil, 2005.

BRASIL. Ministério da Economia, Fazenda e Planejamento. Política Industrial e de Comércio Exterior. Diretrizes gerais. - Brasília: Ministério da Economia, Fazenda e Planejamento, Secretaria Nacional de Economia, 1990.

CALZOLAIO, Aziz Eduardo; DATHEIN, Ricardo. Políticas fiscais de incentivo à inovação: uma avaliação da Lei do Bem. In: ENCONTRO DE ECONOMIA DA REGIÃO SUL, 15. Anais [...]. 2012.

COSTA, Danielle Martins Duarte et al. Reforma do Pis e da Cofins e avaliação dos impactos no desempenho das empresas de Lucro Real utilizando dados em painel. In: CONGRESSO BRASILEIRO DE CUSTOS-ABC. Anais [...]. 2008.

FOGUEL, Miguel Nathan. Diferenças em Diferenças. Avaliação Econômica de Projetos Sociais. São Paulo: Dinâmica Gráfica e Editora, 2012.

MATTOS, Enlinson; ROCHA, Fabiana; TOPORCOV, Patrícia. Programas de incentivos fiscais são eficazes?: evidência a partir da avaliação do impacto do programa nota fiscal paulista sobre a arrecadação de ICMS. Revista Brasileira de Economia, v. 67, n. 1, p. 97-120, 2013.

MENEGUIN, Fernando Boarato; FREITAS, Igor Vilas Boas de. Aplicações em avaliação de políticas públicas: metodologia e estudos de caso. Brasília, DF: Senado Federal, 2013. (Textos para Discussão, n. 123).

NERI, Marcelo; MEDRADO, Andre Luiz. Experimentando microcrédito: uma análise de impacto do Crediamigo no acesso a crédito. Revista Econômica do Nordeste, v. 41, n. 1, p. 133-154, 2010.

O PORTAL TRIBUTÁRIO. Desoneração tributária: incentivos e regimes fiscais específicos. Portal Tributário, 2013. Disponível em: http://www.portaltributario.com.br/guia/incentivosfiscais. htm. Acesso em: 12 out. 2016.

RECEITA FEDERAL DO BRASIL. Instrução Normativa Secretaria da Receita Federal nº 680, de 2 de outubro de 2006. Dispõe sobre o Regime Especial de Aquisição de Bens de Capital para Empresas Exportadoras (Recap). Diário Oficial da República Federativa do Brasil, Brasília, DF, 6 jan. 2006. Disponível em: http://normas.receita.fazenda.gov.br/sijut2consulta/link.action?visao=anotado\&idAto=15536. Acesso em: 08 jun. 2016.

SCALCO, Paulo Roberto; LIPPI, Mariana Klaold; DE ALMEIDA, Marcos Inácio Severo. Preço e renda como determinantes da demanda por bens de luxo no Brasil: um estudo econométrico com produtos importados da Nomenclatura Comum do Mercosul. Revista de Administração da UFSM, Santa Maria, v. 8, n. 3, p. 366-383, 2015. 
THEODORO, M. I. A.; SCORZAFAVE, L. G. Impacto da redução dos encargos trabalhistas sobre a formalização das empregadas domésticas. Revista Brasileira de Economia, v. 65, n. 1, p. 93109, 2011.

THIRLWALL, Anthony P. The balance of payments constraint as an explanation of the international growth rate differences. PSL Quarterly Review, v. 32, n. 128, 1979. 